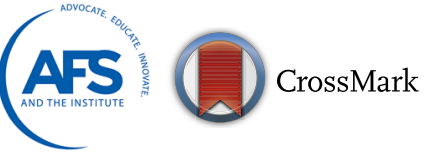

\title{
3D PRINTED SMART MOLDS FOR SAND CASTING
}

\author{
Jason Walker, Evan Harris, Charles Lynagh, Andrea Beck, Brian Vuksanovich, Brett Conner, and Eric MacDonald \\ Advanced Manufacturing Research Center, Youngstown State University, Youngstown, OH, USA
}

Rich Lonardo

Youngstown Business Incubator, Youngstown, OH, USA

Jerry Thiel

University of Northern Iowa, Cedar Falls, IA, USA

Kirk Rogers

GE Additive Customer Experience Center, General Electric, Pittsburgh, PA, USA

Copyright (C) 2018 The Author(s). This article is an open access publication

https://doi.org/10.1007/s40962-018-0211-x

\begin{abstract}
Additive manufacturing, also commonly referred to as $3 D$ printing, stands to transform sand casting with binder jetting technology that can create sand molds with unmatched geometric complexity. With printed sand molds, castings can be optimized with regard to the strengthversus-weight trade-off and structures such as periodic lattices are now available within molds that are not possible with traditional casting technology. However, an increase in design complexity invites more challenges in terms of understanding and managing both the thermodynamics and physics of the casting process. Simulations of castings are more important than ever, and empirical

mold to enable the collection of a diversity of data at manifold locations: temperature, pressure, moisture, gas chemistries, motion of the molds and internal cores (shifting or rotation), and magnetic field. This report describes a proof of concept in which unprecedented levels of process monitoring were integrated-both wirelessly and wired-at strategic locations throughout a printed mold and inside of internal cores. The collected data were used to validate the quality of a casting in situ as well as to provide feedback for optimizing the casting process, mold design, and simulations. A trade-off was explored between sensor survivability and disposability.
\end{abstract} in situ sensor data are required to validate high fidelity computer modeling (e.g., MAGMASOFT ${ }^{\circledR}$ ). One novel solution is to leverage the design freedom of CAD-based solid modeling to introduce unique mold features specifically for housing sensors (Internet of Things) within the
Keywords: $3 D$ printing, additive manufacturing, electronics, sensing, simulation

\section{Introduction}

Sand casting is an economical metal forming process that has been employed to manufacture metal objects since the Shang Dynasty of China over 3000 years ago. ${ }^{1}$ Relative to other forms of casting, sand casting provides a wide range of sizes, complexity, and types of metal alloys. Consequently, the size of the worldwide casting market recently increased to over 100 million metric tons ${ }^{19}$ with sand casting as the predominant method of casting. ${ }^{24}$ The growth and importance of this age-old industry require the leveraging of the latest quality and process controls as well as advances in mold, core, and pattern production to meet global demand and to maintain technical vitality.

Additive manufacturing (AM) or 3D printing emerged as a new manufacturing method since the 1980s, but has generally been limited to production of prototypes. However, the benefits of 3D printing for the casting industry were identified early. ${ }^{5}$ The capability to fabricate complex part 
geometries using layer-by-layer deposition as opposed to traditional subtractive manufacturing now enables production of molds, cores, and patterns that would be otherwise impossible to create without $3 \mathrm{D}$ printing. ${ }^{2}$ One important use of $\mathrm{AM}$ in the casting industry is $3 \mathrm{D}$ printed sand molds which provide complex cavities, good dimensional accuracies, the ability to insert components within the casting and/or mold, and an increased freedom in the design of the metal delivery system (gating, sprue, risers, etc.). Sand printers use binder jetting technology to ink jet a binder resin into a catalyst-mixed sand. After printing a layer, a new layer of sand is re-coated over the previous layers and the process repeats until the mold and/or cores are completed. The furan binder chemistry typically used involves a condensation-type curing and cross-linking reaction which are both exothermic and chromophoric. The temperature increases in the mold as it cures are generally less than $20{ }^{\circ} \mathrm{C}^{3}$ which could allow for the survival of electronics or sensors inserted into the mold during printing.

More generally, substantial research has been focused on 3D printed sand molds including the material systems (e.g., binders and silica), ${ }^{7,18,21}$ properties such as surface finish and porosity, ${ }^{2,15,22}$ complex multi-material structures, ${ }^{16,17}$ modeling of the process ${ }^{12}$ and even sensing in smart sand molds ${ }^{8}$ in which temperature sensors were inserted into 3D printed sand molds, and the survival and utility of the sensors were evaluated. An entire community has researched ink jetting, the foundational process of binder jetting, and the process is well understood and modeled. ${ }^{6,9,13}$

While the inherent benefit of AM-enabled casting is the freedom of geometry, the accompanying challenge is the increased complexity of the casting process and potential reduction in part manufacturability. To overcome the challenges, casting simulations are required to predict the flow of metal potentially causing entrapment of gases or erosion of sand from interior surfaces. In the context of 3D printed molds, simulations are required with the nearly unlimited design freedom enabled by 3D printed molds. Furthermore, the resulting complex surfaces of the cavity within the mold can lead to difficult-to-predict heat dissipation which directly affects solidification. As shown in Figure 1, increased complexity and large surface areas can easily result in casting problems including premature solidification and formation of such defects as cold-shuts and lack of fusion. Lattices with smaller struts and therefore higher surface area (Figure 1, right) tend to solidify too quickly, while lattices with a larger strut size and lower surface area (Figure 1, left) fill completely despite the two designs having the same metal volume. This example shows both the profound benefits of AM-enabled casting with geometries not previously possible while simultaneously highlighting the challenges and motivation for high fidelity simulations and sensing.

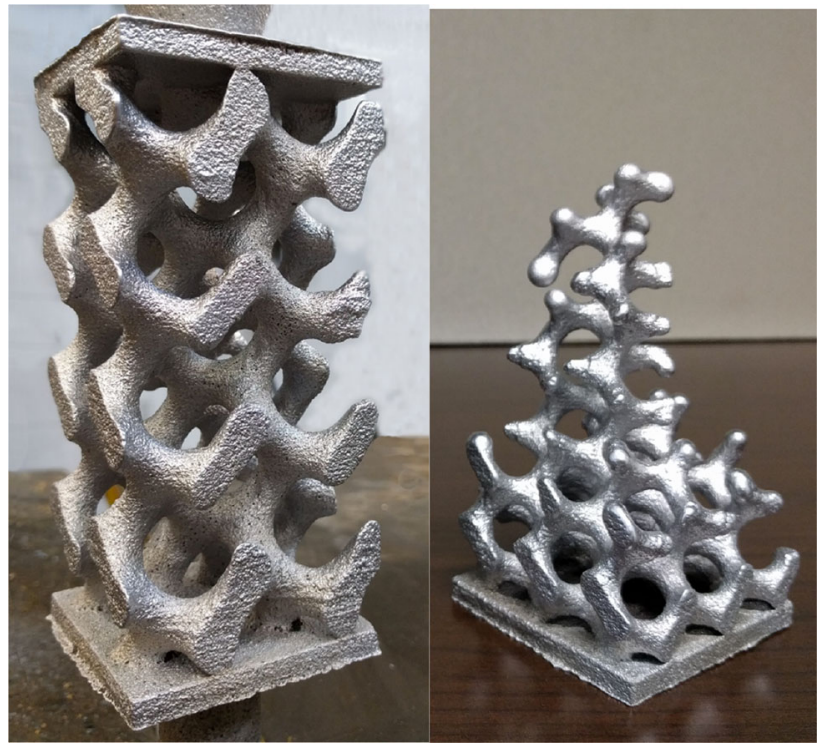

Figure 1. Complex aluminum structures with varying degrees of casting success. Left: Successful lattice casting of large strut (9.53 $\mathrm{mm}$ diameter) gyroid; right: incomplete gyroid casting with smaller strut sizes (6.35 mm diameter). Both castings had designed external dimensions of $63.5 \times 63.5 \times 139.7 \mathrm{~mm}$ and mass $0.5 \mathrm{~kg}$.

\section{Design of an Instrumented 3D Printed Sand Mold}

This effort included leveraging an "Internet of Things" strategy for nontraditional sensing of AM-enabled castings (a) in molds and (b) in a core in order to collect data to fuel the analytics necessary to advance in situ evaluation, model validation, and casting qualification. In concert with advances in modeling, the comprehensive collection and integration of process measurements will enable improved simulations, in situ quality control, and possibly expedite the qualification of casting designs and mold printing processes (rather than resource-consuming physical trialand-error tests). Wired thermocouples have only infrequently been published in research with examples including, ${ }^{4,8,10}$ but the use of these sensors is common knowledge in the foundry industry to optimize casting processesalbeit not documented in open literature. Alternatively, Bluetooth systems have been improving over the last two decades to the point now that a sensor system with an ARM processor (used in most smartphones as of 2017), a Bluetooth radio, and an arsenal of miniaturized sensors can be now be integrated onto a small printed circuit board that is smaller than a postage stamp. The inevitable marriage of this Internet of Things sensing capability with the ancient art of sand casting has not been reported to the best of the authors' knowledge and is presented here with a sensor system including 12 degrees of sensing. Specific cavities were included in the molds to integrate sensors and collect high fidelity data including environmental metrics (temperature, pressure, humidity), acceleration, rotation, and magnetic flux. 


\section{In-Mold Sensing for Casting Process Simulation Studies (Wired Thermocouples)}

To improve the understanding of the physics of complex castings, an instrumentation methodology was created in which high temperature type $\mathrm{K}$ thermocouples were inserted into purpose-designed slots within a parting line at a variety of depths from the cavity. All thermocouples (GeoCorp, Inc, Huron, $\mathrm{OH}$ ) were factory calibrated and verified to meet the special limits of error tolerances of ASTM E230. The first objective of the thermocouples was to set up a correlation baseline between the experimental setup and the simulation model. The second objective of the temperature data (versus distance) was to identify the operational region in sand molds for the integration of wireless electronics. Three scenarios exist for the positioning of the electronics:

1. in a location where the temperature never exceeds the maximum operating temperature of the circuit $\left(85^{\circ} \mathrm{C}\right)$ and data collection would be continuous,

2 . in a location where the temperature would exceed the operating temperature but not the maximum storage temperature $\left(150{ }^{\circ} \mathrm{C}\right)$ allowing for a short duration of data collection and guaranteeing the survival and recyclability of the circuits, or

3 . in a location where both the maximum operating and storage temperatures would be exceeded but in closer proximity to the cavity providing more direct data acquisition but for only a short period-until the sensor is sacrificed.

The final case would require immediate wireless communication as recovery of the circuits at shakeout would not be possible. However, the data collected could be in difficult-to-reach locations in a mold such as an internal core. The aim of the thermocouple study was to provide the appropriate distances from the cavity to determine the positioning of the wireless sensors.

Figure 2 illustrates a 3D printed sand mold with thermocouple cavities at varying distances from a dummy casting of a hollow cylinder. Eight thermocouples were included within the parting line in the main mold structure. One thermocouple was placed at the mold-metal interface such that during the casting molten aluminum was in contact with the thermocouple. Data from this thermocouple were collected and presented with the knowledge that the calibration may have been compromised the moment molten aluminum contacted the sensor. The other seven thermocouples were increasingly spaced from the cavity in a staggered manner at $2.5,5,10,20,30,40$, and $50 \mathrm{~mm}$ rotating clockwise as shown in the bottom left of Figure 2 . Figure 2, bottom right, shows the thermocouples encased with continued assembly of the mold. One final molding piece capped these off suspending a vertical core within the cavity. Data were collected during the $24 \mathrm{~h}$ after the end of pouring and included four measurements per second for the first $1.5 \mathrm{~h}$ and one measurement every minute for the next $22.5 \mathrm{~h}$. This allowed for manageable data files while maintaining fidelity during the period of more thermal activity.

\section{In-Core Wireless Sensing}

The continuous technological advances in miniaturization of electronics and sensors enable a complete computational platform with a radio and an array of sensors in a footprint that can be easily accommodated within a sand mold or core. Dialog IoT Sensor systems include an ARM processor with substantial computational bandwidth, but more importantly the system includes a low power Bluetooth radio which can allow for the collection of data in difficultto-reach positions within a sand mold or core and include sensing for:

1. three axes of magnetic field,

2. an inertial measurement unit providing three axes each of rotation and acceleration, and

3. an environmental sensor with relative humidity, pressure, and temperature.

These commercial Bluetooth sensor systems can be buried within cores and are sufficiently inexpensive to be considered disposable. As a casting is poured, the metal that will surround the core will inhibit radio frequency communication required to transmit collected sensor data. In the case of the experimental casting, there was a sand-only path for the signal to exit the mold even after the risers had filled and the casting completed. The small electronics were not expected to survive beyond several minutes. Temperature increase was simulated for the sensor cavity which was predicted to exceed $350{ }^{\circ} \mathrm{C}$ at $750 \mathrm{~s}$ after the casting -well above the maximum sustained storage temperatures of $150{ }^{\circ} \mathrm{C}$ (predicted to exceed at $175 \mathrm{~s}$ ) and maximum operating temperature of $85^{\circ} \mathrm{C}$ (predicted to exceed at $110 \mathrm{~s}$ ). However, the electronics were expected to tell the story of what had occurred to the core in the early stages of the pour (first $180 \mathrm{~s}$ ) before the electronics were affected by the harsh conditions. The sensors are shown in Figure 3 before and after encapsulation in the sand core. The multi-sensor electronic unit, shown in center, costs approximately \$45 USD and includes all of the aforementioned sensors, as well as an on-chip processor (used in most contemporary cell phones) to read the sensors and transmit data. At this price point, the multi-sensor electronic unit is easily considered disposable for low volume research applications and could be manufactured in-house at an even lower cost.

Among the different types sensors that can be provided in a miniaturized format, linear acceleration and rotation can be used to measure relative motion of mold components including identifying potential core shifts. In situ 

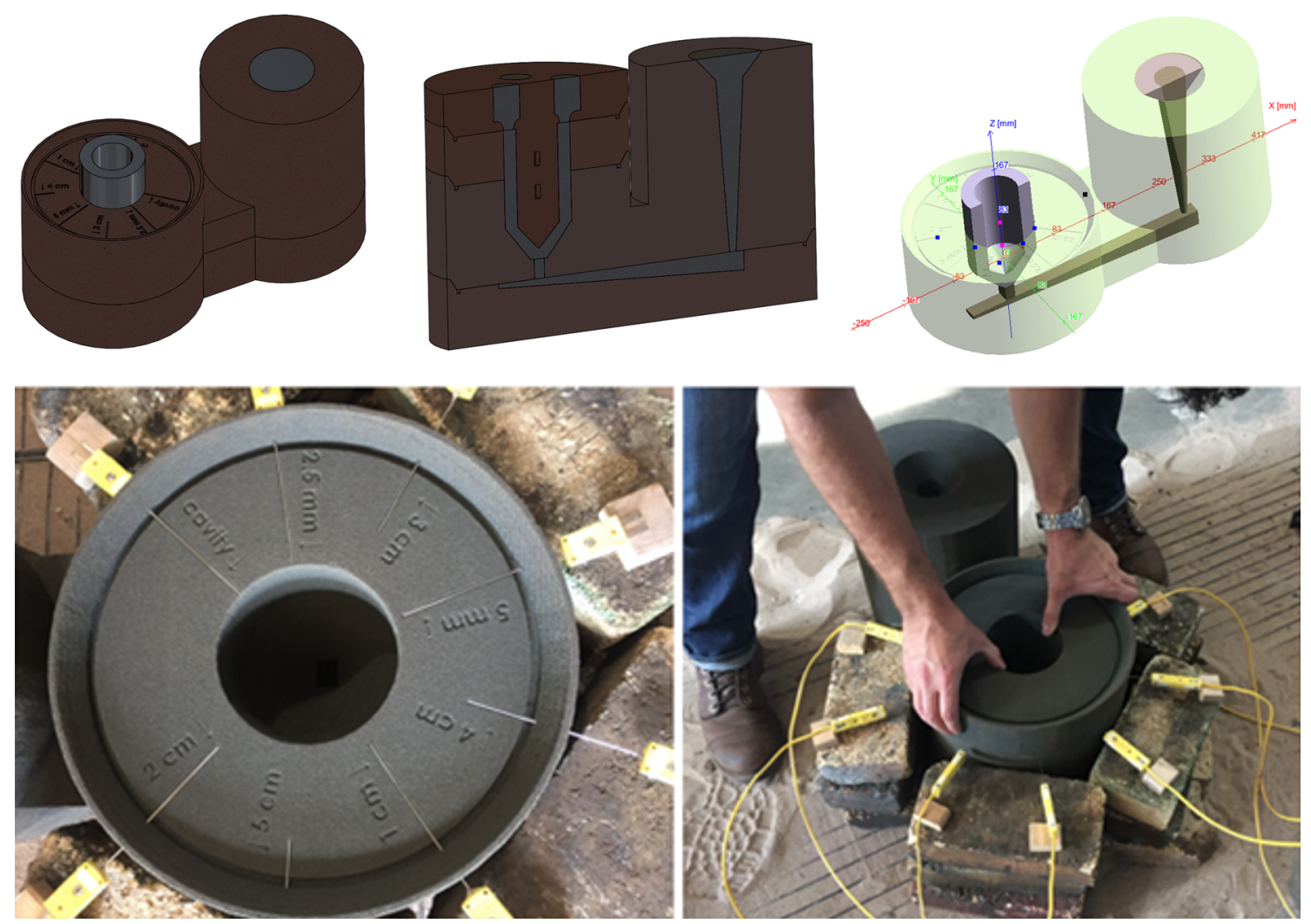

Figure 2. Top: CAD renderings of the test part in the mold with the thermocouple parting line exposed (left), a section view revealing the Bluetooth pockets (center), and a partial section view showing the location of thermocouples in the simulation model (right). Blue points refer to wired thermocouple locations, while pink points refer to Bluetooth thermocouple locations. Bottom: Assembly of AM-enabled sand mold in the foundry with embedded thermocouples at varying distances from the cavity ranging from 0 (metal contact) to $5 \mathrm{~cm}$.

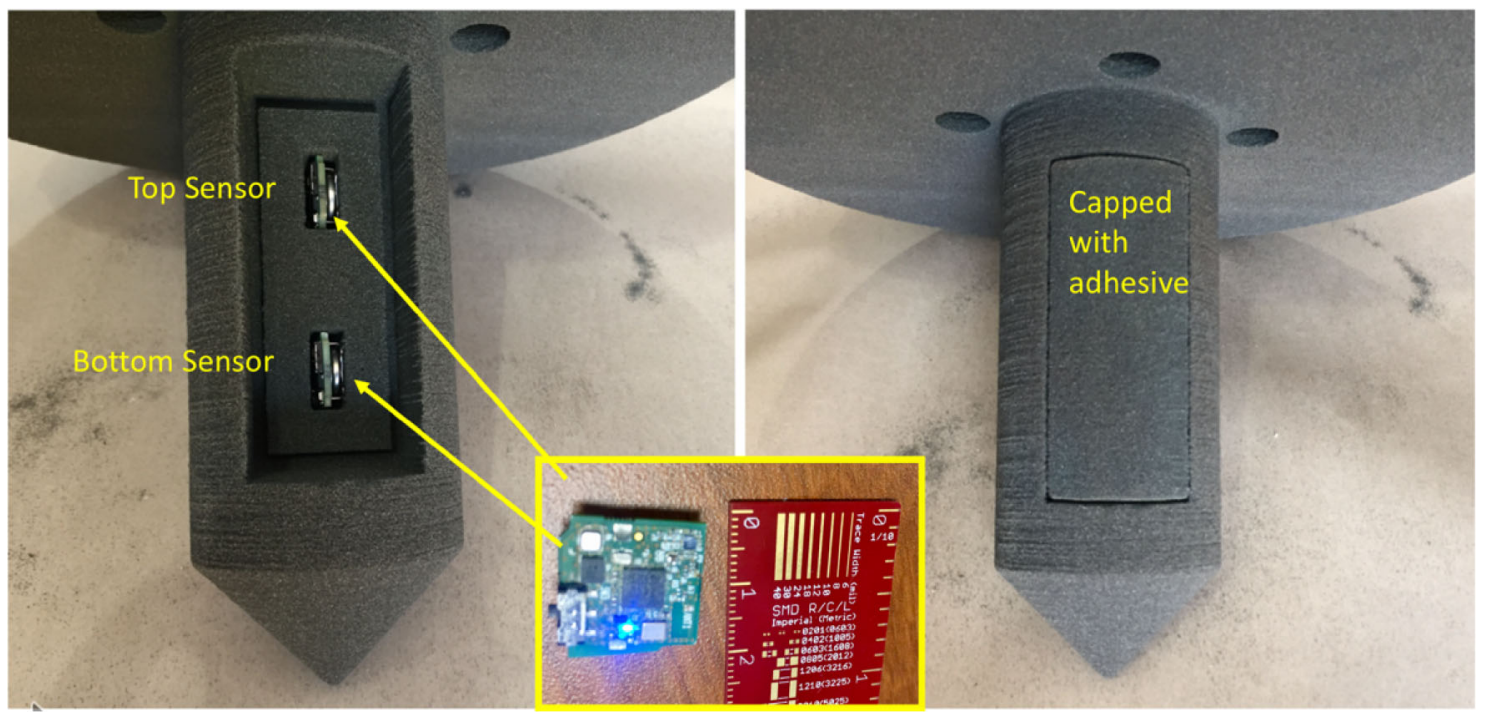

Figure 3. An internal core with two embedded Bluetooth sensor systems subsequently capped for protection from the molten metal. Sensor cavities are $18 \times 18 \times 8 \mathrm{~mm}$.

temperature sensing (or lack thereof) can verify that nearby cavities have been filled with metal as anticipated or identify cold shut defects formed due to excessive heat losses during filling. Electrically conductive fluids, such as molten metal, generate magnetic fields when in motion that can be measured with a magnetometer. Previous studies have focused on the use of static or dynamic magnetic fields to stir molten metal in order to improve metal purity, 
reduce solidification defects, control grain size, and control crystal orientation. ${ }^{11,20,24}$ However, another previous study examined the use of a magnetic probe to measure melt velocity and mass transfer. ${ }^{14}$ As molten metal was passed around a permanent magnetic cylinder, a changing voltage was read and translated into velocity and mass transfer. One potential application of measuring magnetic fields in castings is to provide an immediate and indirect detection of metal in runners - two sensors of which at a known separation could provide an indication of melt velocity.

To verify that wireless signals can be reliably transmitted through furan resin bonded sand preliminary experiments were completed as shown in Figure 4. Spherical sand cores were created with varying diameters to measure the attenuation of the wireless signals through the sand and binder system. Although the wireless connection could be maintained through the bonded sand, a slight reduction in signal strength was recorded from the sensors, embedded up to $14 \mathrm{~cm}$ deep. Care must be taken then for large molds that could result in significant attenuation and disconnections between a data recording device and the embedded sensors. Furthermore, the distance between the recording device and the mold also plays a significant factor in signal reception. The closer the recording device is to the mold, the better in terms of the reliable collection of data. Future work will further investigate critical values related to mold thickness, receiver distance, and signal strength.

\section{Results and Discussion}

The results of this effort can be separated into two sections: ${ }^{1}$ the thermocouple comparison with MAGMASOFT $^{\circledR}$ which shows that both physical instrumentation and simulation are necessary to gain a strong understanding of the process physics and ${ }^{2}$ a demonstration of the diversity of sensor data which can be collected in an internal core with wireless sensors-providing data acquisition, to the best of the authors' knowledge, never previously available.
The sample casting is shown in Figure 5. In the picture, two data acquisition devices are elevated above the mold on a step ladder and successfully collected data from the embedded Bluetooth sensors starting $2 \mathrm{~h}$ prior to the casting and lasting until approximately 2 min after pouring. The duration of the pour-melt first entering the sprue until all risers were filled-was $11 \mathrm{~s}$, and Bluetooth data were continuously collected on the two sensors for 115 and 135 s afterward until each sensor expired.

\section{Embedded Wired Thermocouples}

Eight type $\mathrm{K}$ thermocouples were placed into the mold along a parting line in prefabricated slots at varying distances from the casting cavity. Here, the use of computer aided design principles and 3D printing for mold fabrication enables unprecedented control of thermocouple placement. Thermocouple data were collected before, throughout, and for several hours after pouring. Similarly, temperature profiles were calculated in MAGMASOFT ${ }^{\circledR}$ through the use of virtual thermocouples placed at matching locations (refer to Figure 2). Small discrepancies between experimental and simulated curves could be attributed to inexact ambient conditions, unaccounted heat losses during transfer of metal to the mold, and lack of experimentally verified thermophysical properties of the 3D printed sand system used in this experiment. Overall, as shown in Figure 6, there is a strong agreement between predicted and actual temperature distributions throughout the mold over a relatively long period of time. Such agreement between data at the thermocouple locations demonstrates casting process simulation as an indispensable tool for studying the multi-physics of the entire metal casting system.

Second order temperature effects are also seen early in the thermal evolution as a shift in the temperature wave that propagates through the mold. In the close-up Figure 7, the effect is easily seen in the experimental data. Here, it appears as an interruption in the temperature curve
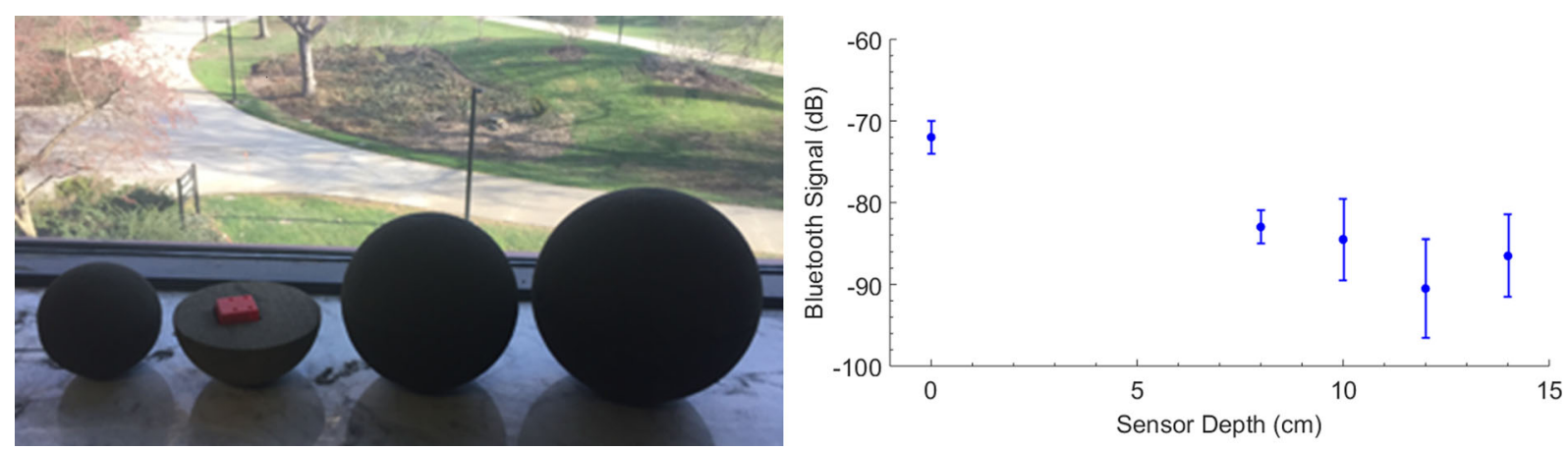

Figure 4. Spherical sand cores used for evaluation of electromagnetic propagation of Bluetooth signals through the sand media (left) and attenuation with $d B$ versus depth in centimeters (right). 


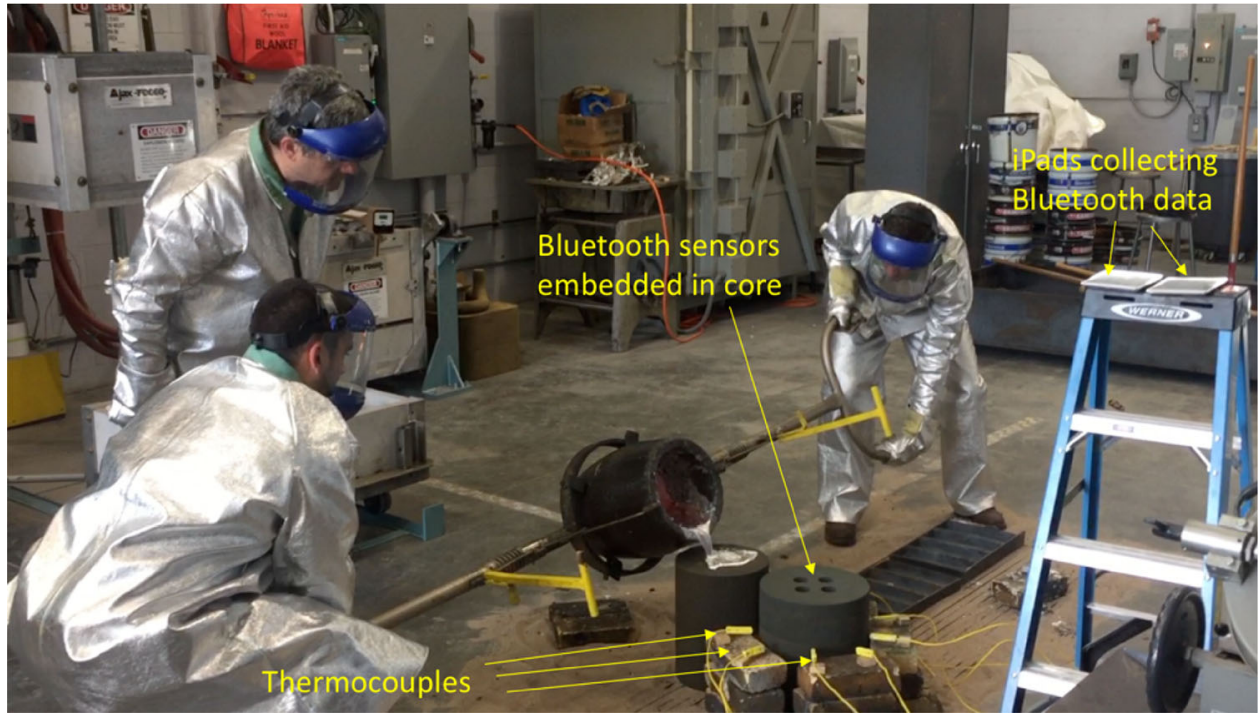

Figure 5. Casting with both wired and wireless in situ sensors.

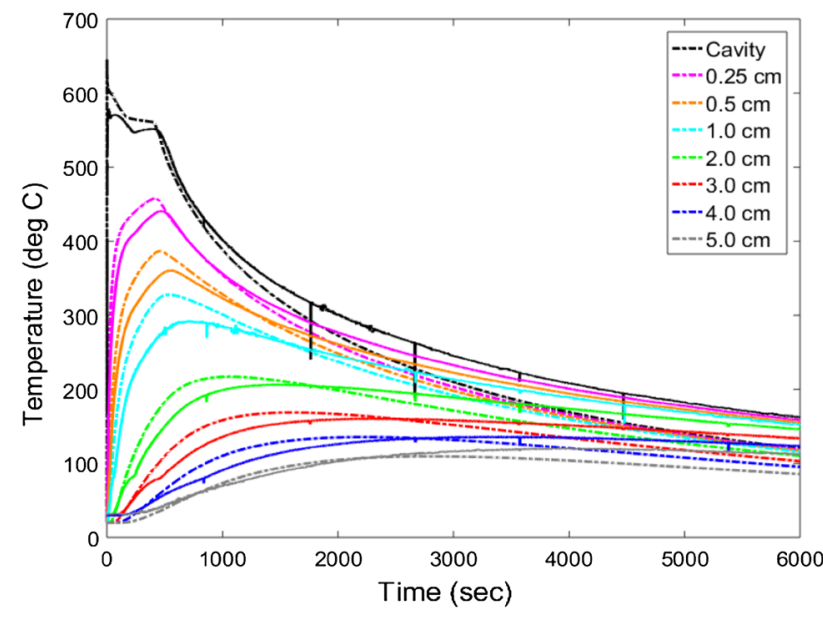

Figure 6. Comparison of experimental and simulated cooling curves recorded at varying distances from the casting cavity. approximately between 80 and $90{ }^{\circ} \mathrm{C}$. In the simulated data, a similar second order effect is seen although it is significantly less pronounced and occurs at a slightly higher temperature-approximately $100{ }^{\circ} \mathrm{C}$. These effects are highlighted with red circles in Figure 7. A possible explanation for this effect may be evaporation of moisture in the mold as the temperature rises, while the difference between the experiment and simulation may be attributable to the difficulty in quantifying and simulating moisture content within the mold and its surroundings.

\section{Bluetooth Sensors Within Difficult-to-Access Cores}

The Bluetooth sensor systems are capable of operating to a maximum of $85^{\circ} \mathrm{C}$ and can be stored up to $150{ }^{\circ} \mathrm{C}$. In the castings, both locations of the sensor systems were $2.27 \mathrm{~cm}$

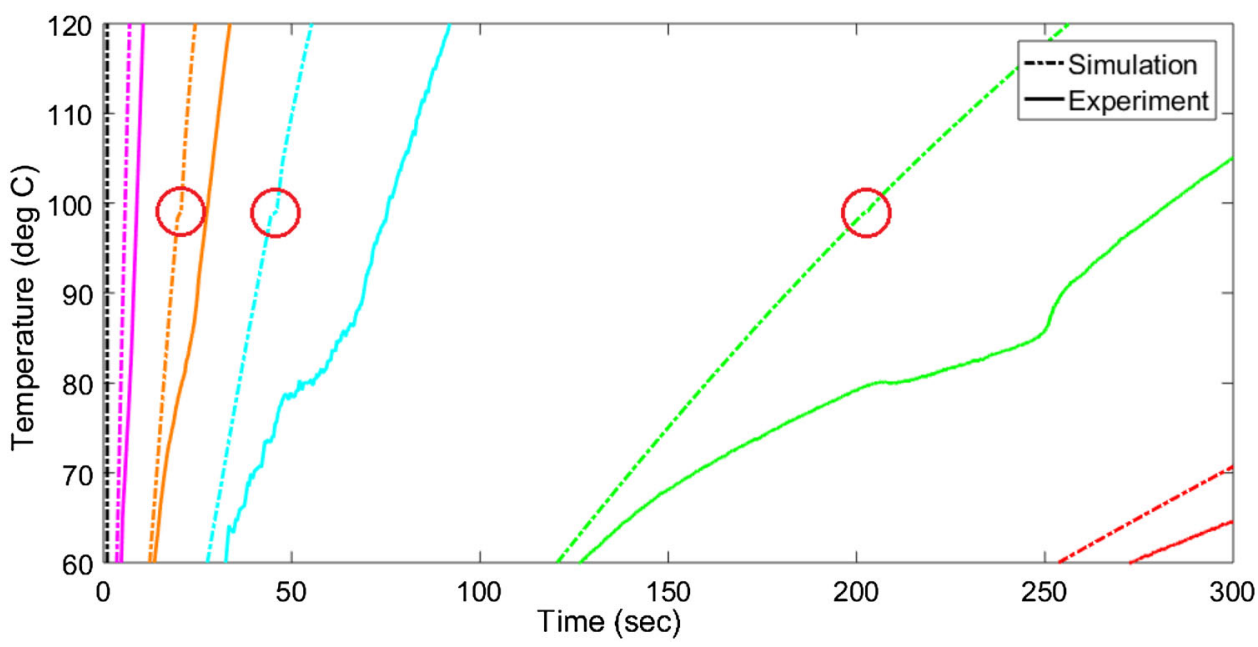

Figure 7. Close-up showing second order effects seen in both simulation and experiment. 
from the metal cavity and consequently were not expected to survive in an aluminum casting with molten metal poured at $700{ }^{\circ} \mathrm{C}$. MAGMASOFT ${ }^{\circledR}$ simulations estimated a peak temperature at the site of the electronics to be $400{ }^{\circ} \mathrm{C}$ at $750 \mathrm{~s}$ (Figure 8) with the circuit board slightly protected within a small air cavity. The temperature was estimated to reach $85{ }^{\circ} \mathrm{C}$ after $100 \mathrm{~s}$ and $150{ }^{\circ} \mathrm{C}$ after $155 \mathrm{~s}$ resulting in the complete destruction of the chip, the battery, and the depopulation of the circuit board with soldering reflow. As predicted, the two circuits operated for 115 and $135 \mathrm{~s}$ after the start of the pour before succumbing to the high temperature. As with the wired thermocouples, the simulated temperature curve closely tracked the measurements by the Bluetooth sensors until the sensors were no longer capable of recording and/or transmitting data.

\section{Acceleration Measurements}

The inertial measurement unit captured three axes of acceleration. The data are presented in Figure 9. A green vertical dashed line is entitled "scraper tapped" and indicates a time prior to the pour when a tool was used to physically disturb the foundry floor-this time point in the acceleration data was later correlated with video and used to provide a common timebase with which to synchronize data. Near the end of the time plotted, sudden acceleration in $\mathrm{X}$ and $\mathrm{Y}$ directions is measured indicating movement. However, as these measurements are taken as the temperature of the sensor begins to exceed the operating temperature, these final motions are suspect and could be a result of the inertial measurement unit beginning to fail due to the harsh conditions. Understanding the behavior as seen in the last minute will be the focus of future work.

\section{Gyroscope Measurements}

In addition to linear acceleration, the inertial measurement unit included a gyroscope which provided sensitive rotational measurements inside of the hanging core. The top Bluetooth sensor was suspended $4.5 \mathrm{~cm}$ below the top of the mold, while the bottom sensor was $8.5 \mathrm{~cm}$ below the top of the mold (refer to Figure 4). Rotation was measured in three axes by both sensors. The maximum rotational swing (the difference between maximum and minimum rotation) was found to occur around the $\mathrm{Z}$ axis in the bottom sensor (note: that is the $\mathrm{Z}$ axis of the sensor's native coordinate system, not necessarily indicating a vertical axis). As shown in Figure 10, a maximum rotational swing of 0.05 degrees was measured, translating to just over 100 microns of lateral movement. This is a clear demonstration that rotations can be precisely measured within a sand mold and the measured shift is well within the precision of the S-MAX ${ }^{\mathrm{TM}} 3 \mathrm{D}$ sand printer. Care must also be taken to ensure that the sensor does not rotate independently of the mold and future work will focus on design aspects relating to this.

\section{Magnetic Field Measurements}

The magnetic sensor of the top sensor system did not work upon encapsulation in the sand mold (prior to the high temperatures of the casting), but the experiment was continued as: (a) the bottom sensor magnetometer was working correctly and (b) the magnetometer was not expected to provide interesting data (just an added bonus). Figure 11 illustrates the three axes of the magnetic flux, and the two dotted lines are included for synchronization with the start and end of the pour. For all three axes, the magnetic flux changes abruptly during filling of the mold, indicating that a magnetic field was generated as molten metal flowed into

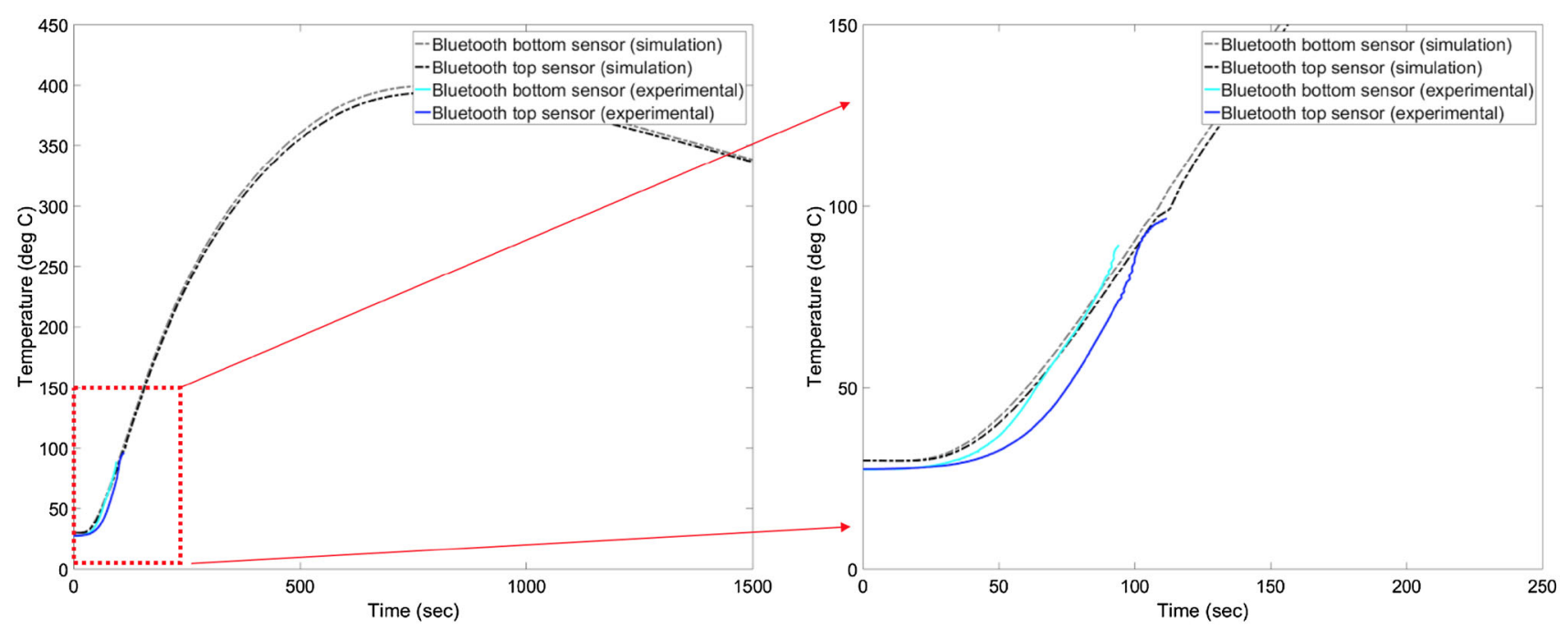

Figure 8. MAGMASOFT ${ }^{\circledR}$ simulations versus sensor measurements. The sensor data are terminated early as the electronics did not operate above $90^{\circ} \mathrm{C}$ and were eventually destroyed above $250^{\circ} \mathrm{C}$. 


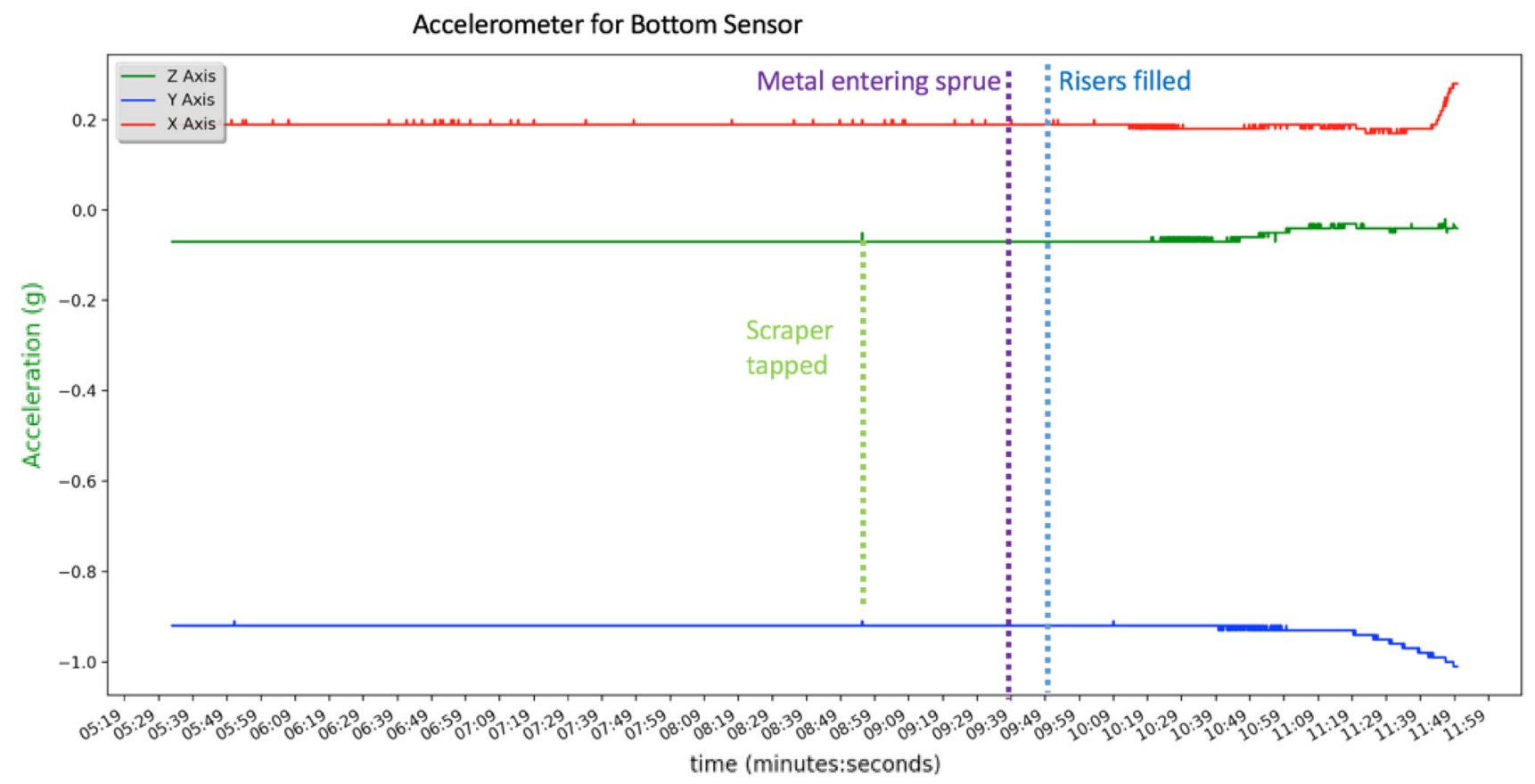

Figure 9. Three axes of acceleration measured by the bottom Bluetooth sensor.

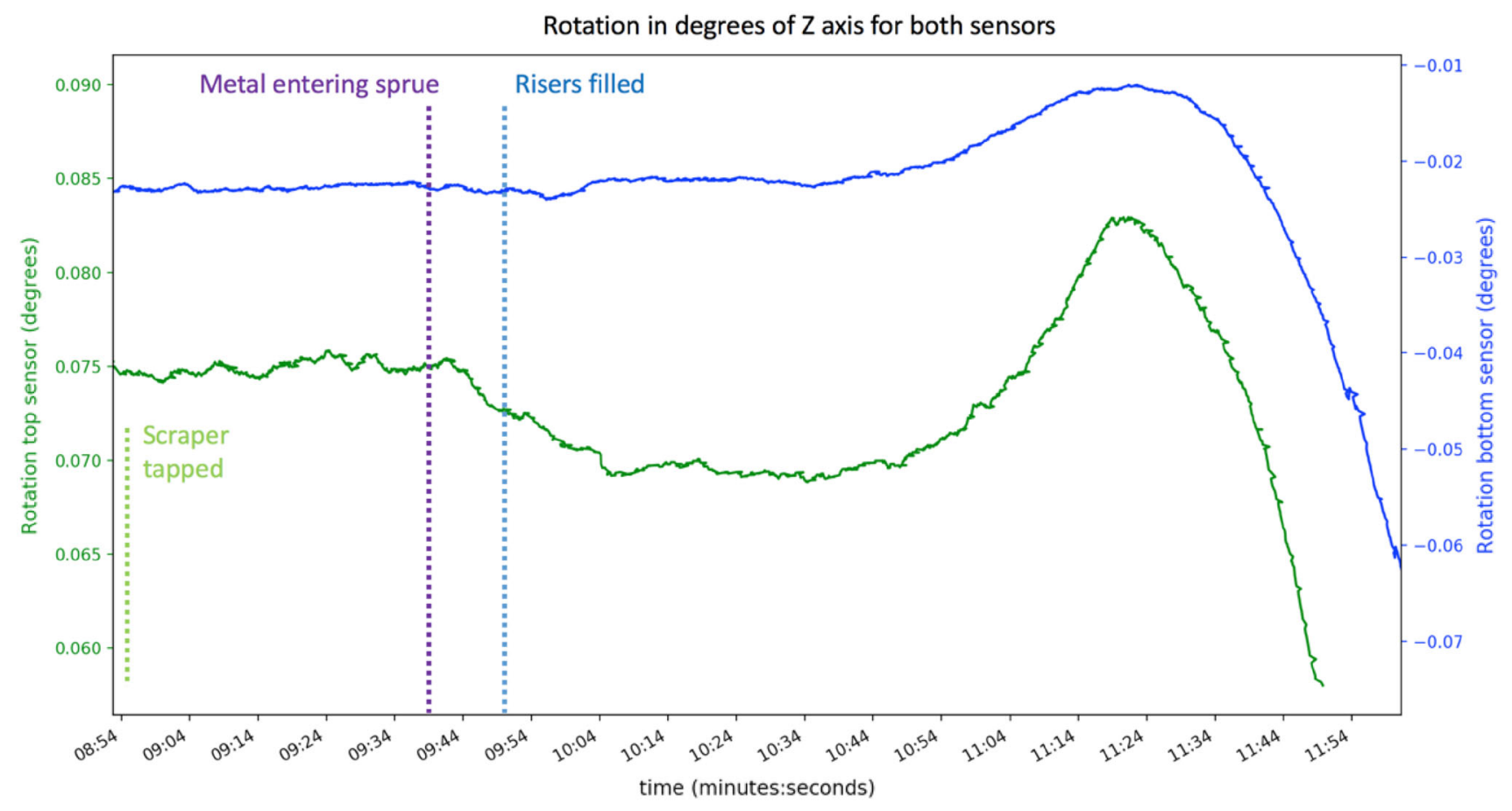

Figure 10. Gyroscope measurements for the both sensors around their $Z$ axes.

and through the cavity. After the metal cavity was full, the magnetic flux changed again, this time more graduallybeginning approximately 1 min after filling was complete and lasting until the sensors expired.

This unexpected magnetometer result demonstrates a potential method to instantaneously and indirectly monitor the fill of internal cavities or runners without the delay associated with temperature sensing. Measurements taken as metal passes nearby at two sensor locations of known separation along a mold runner could allow for the calculation of the velocity of the molten metal. By measuring and subsequently optimizing the speed of the metal entering the mold cavity, the quality of the casting could potentially be improved by reducing sand erosion or gas entrapment, the subject of future collaborative work with 


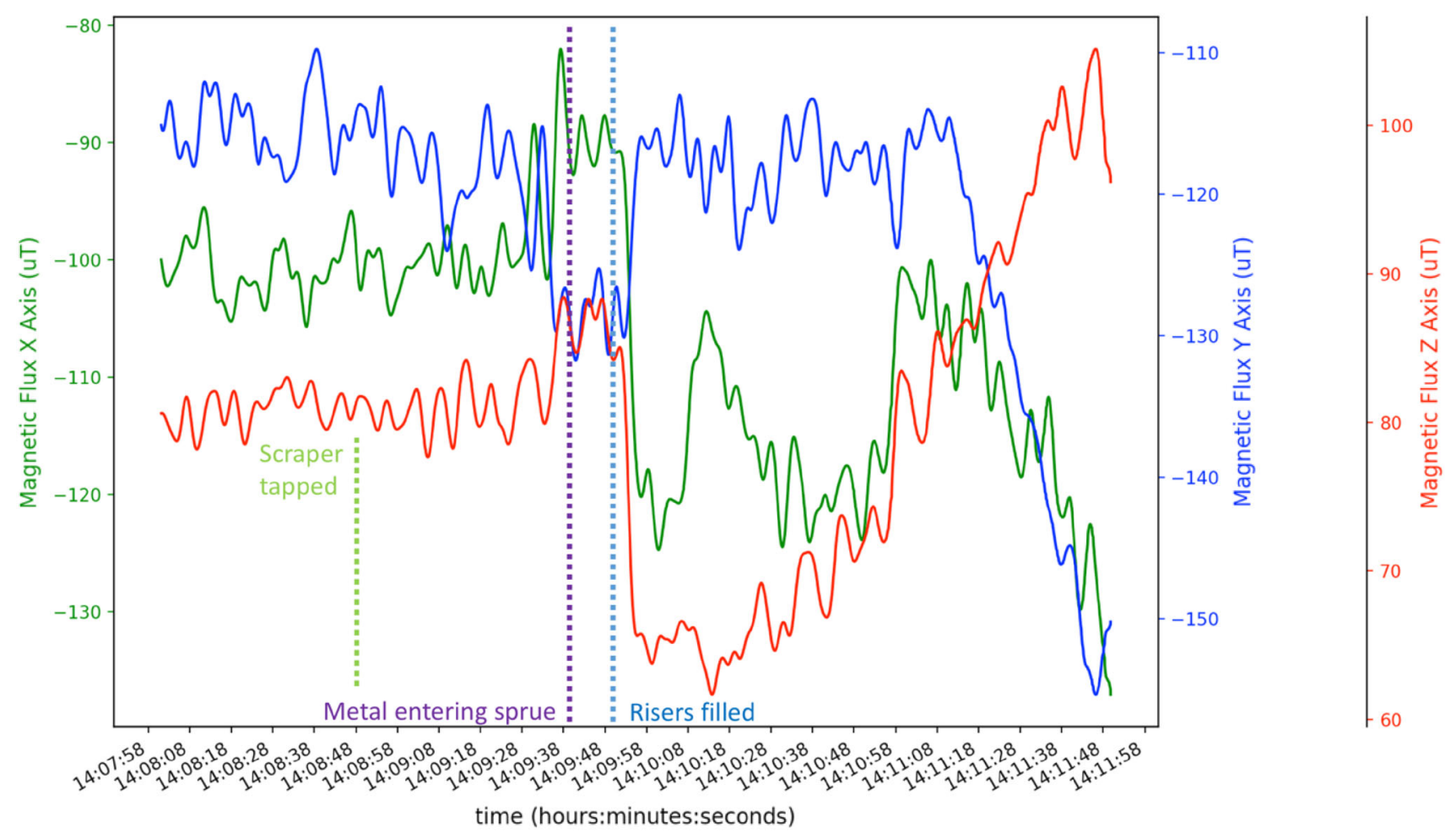

Figure 11. Magnetic field strength in three axes from the sensor in the bottom.

Guha Manogharan at Pennsylvania State University who identified the concept. Further research is needed to determine if this is related to the motion of the metal front and could be used as an in situ tool for immediately detecting metal in different chambers in the mold. Furthermore, the magnetic field changes that occur over $60 \mathrm{~s}$ after the pour completes could possibly provide insights into the solidification process, and this hypothesis is also the subject of future work.

\section{Environmental Measurements}

Temperature, relative humidity, and pressure were all captured, and the results were similar between the top and bottom sensors. The bottom sensor was immersed on all but the top side by metal and was consequently the first to detect temperature changes and the first to succumb to the harsh conditions. The top sensor continued working for an additional $20 \mathrm{~s}$ after the bottom sensor expired. Both sensors measured temperature above $90{ }^{\circ} \mathrm{C}$ (beyond the quoted operating temperature of the sensor and radio) and registered changes in humidity and pressure as well (Figure 12: only top sensor shown). The bottom sensor provided similar data. The temperature as shown in Figure 12 closely matches the MAGMASOFT ${ }^{\circledR}$ simulations. The humidity presumably increases due to the boiling off of moisture in the sand, and the pressure correspondingly increased and then excess pressure released through the top of the suspended core.
During mold filling, from the start of pouring until the risers were full, both pressure sensors registered a change in pressure with values initially climbing along a parabolic trajectory and then dropping after approximately $2 \mathrm{~min}$ (Figure 13). The conjecture regarding this behavior is that as the sand temperature increased, moisture and binder in the sand evaporated and thus increased the pressure in the core which would be almost entirely enclosed by molten metal. However, after most or all of the initial moisture content was exhausted through evaporation and permeated out of the core, the pressure returned to ambient as shown on the top sensor.

Both pressure sensors registered changes as the metal flowed during the pour and possibly during the immersion of the core itself-after the start of the pour but prior to the complete filling of the risers. As the bottom sensor was surrounded laterally but also from below with molten metal, the pressure reading arrived slightly earlier and reached a higher value of $101 \mathrm{kPa}$ versus $100.5 \mathrm{kPa}$ in the top sensor. The value of pressure sensing in molds or in the core could allow for indirect measurement of the permeability of the bonded sand and the optimization of the process and materials (binder, sand, venting, etc.) by reducing localized high pressures in the sand.

\section{Conclusions}

Due to recent technological advancements that are dramatically reducing the size and cost of sensors, integration 


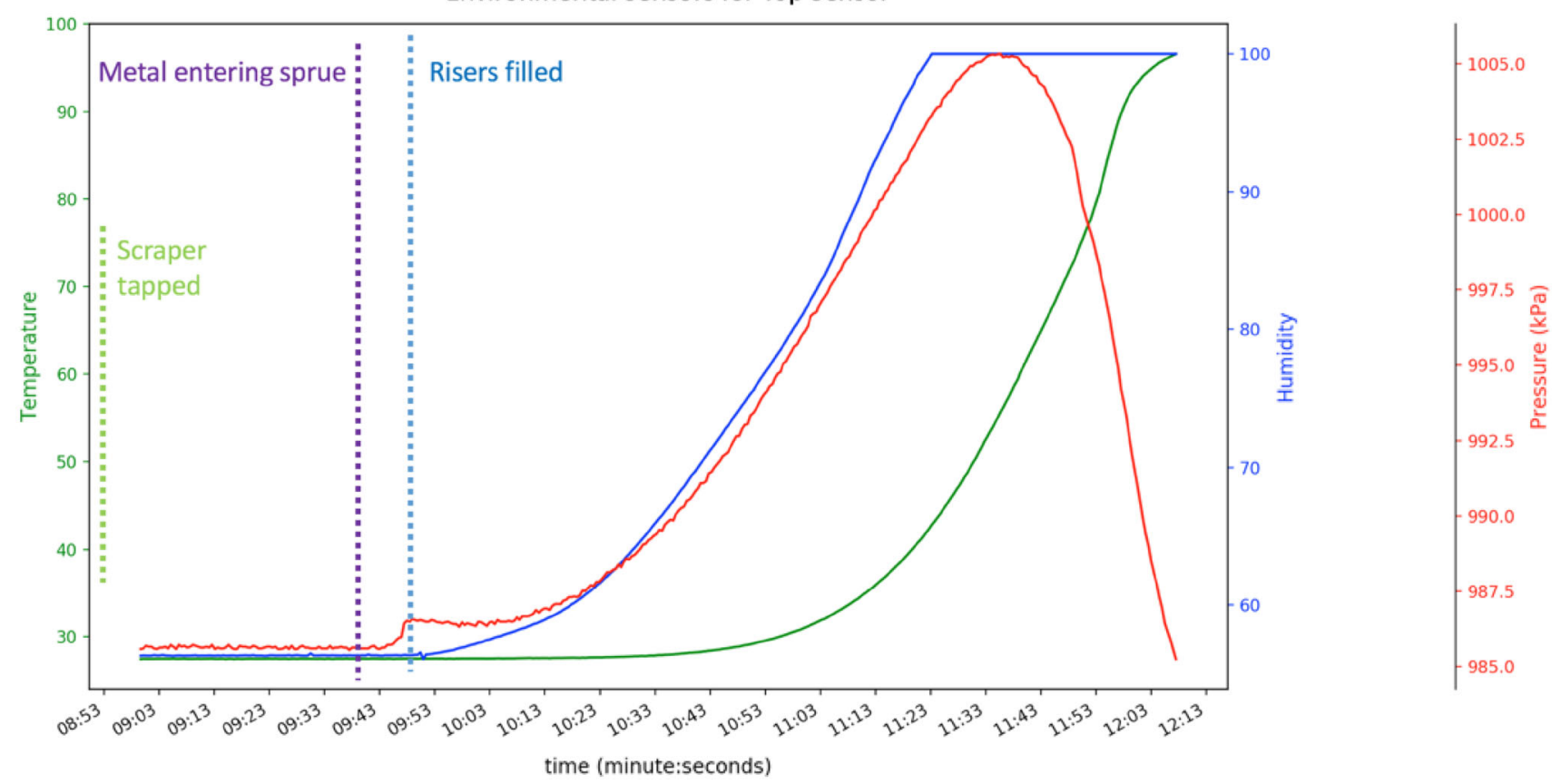

Figure 12. Environmental readings for the top sensor-humidity (blue), pressure (red) and temperature (green).

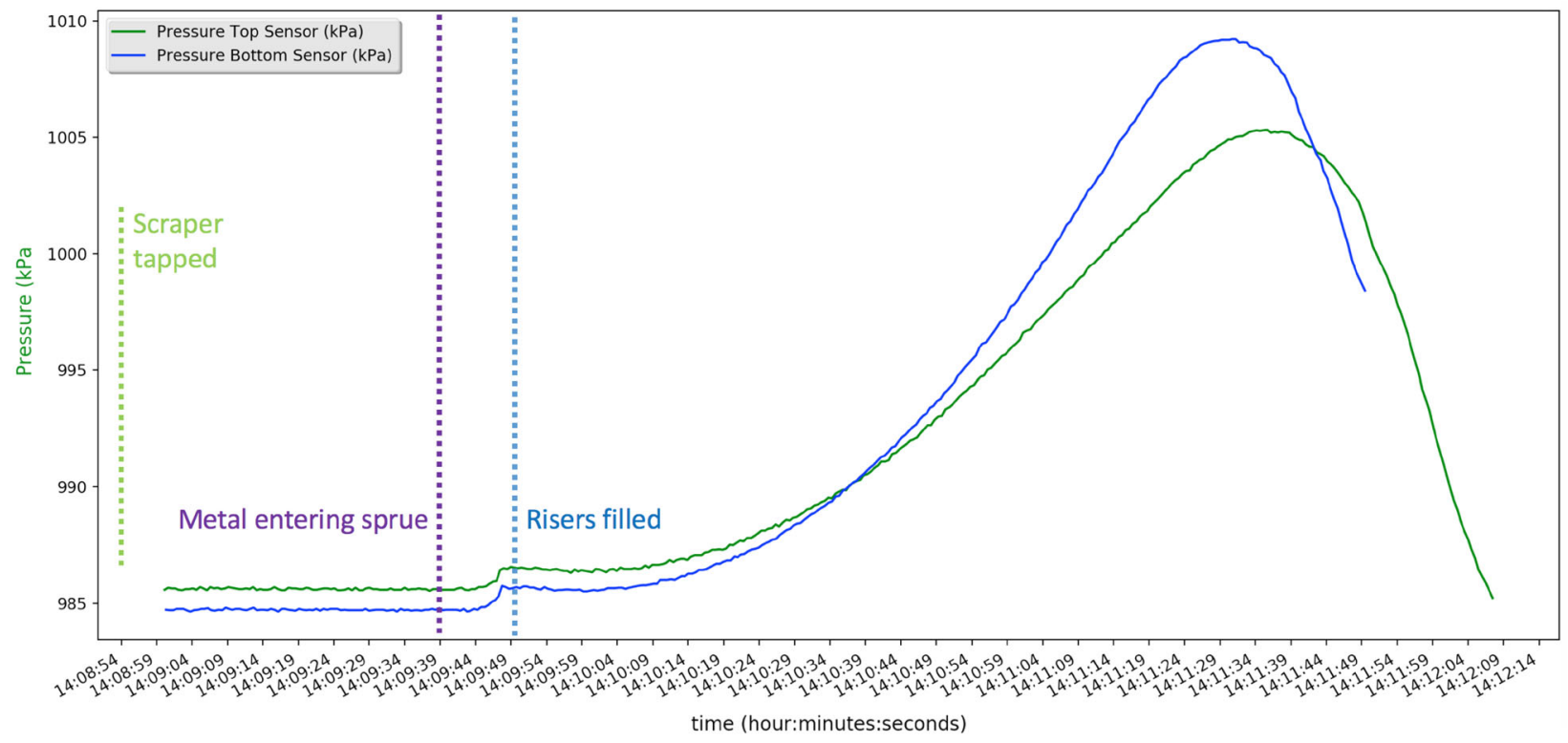

Figure 13. Pressure readings for both the top and bottom sensors.

of high fidelity sensing is inevitable in modern industrial practices and metal casting is no exception. This age-old process stands to benefit from both $3 \mathrm{D}$ printing as well as advanced sensing, and in many cases from the introduction of both transformative technologies simultaneously. With today's wireless sensors, data from deep within molds and difficult-to-access regions are readily obtainable, particularly when paired with the design and manufacturing freedom afforded by 3D printing. This study has demonstrated the utility of leveraging $3 \mathrm{D}$ printing to enable the use of sensors which can provide primary data as well as validate complex computer models. This is an early look at how coherent use of advanced manufacturing, simulation, and sensing can revolutionize a steadfast practice.

\section{Acknowledgements}

This research was supported by several institutions. We thank our colleagues from America Makes for partial resourcing from the ongoing Additive Manufacturing for Metal Casting (AM4MC) project. We would like to thank the Friedman Endowment for Manufacturing at 
Youngstown State University. The Department of Art at Youngstown State University provided the building that houses the foundry that completed all work and we appreciate their involvement. Finally, we thank MAGMA Inc. for the donation of an educational software license and expert advice. All statements of fact, opinion, or analysis expressed are those of the authors and do not reflect the official positions or views of any U.S. Government agency. Nothing in the contents should be construed as asserting or implying U.S. Government authentication of information or endorsement of the author's views.

Open Access This article is distributed under the terms of the Creative Commons Attribution 4.0 International License (http://creativecommons.org/licenses/by/4.0/), which permits unrestricted use, distribution, and reproduction in any medium, provided you give appropriate credit to the original author(s) and the source, provide a link to the Creative Commons license, and indicate if changes were made.

\section{Funding}

Funding was provided by Air Force Research Laboratory (4063.001).

\section{REFERENCES}

1. N. Barnard, Bronze Casting and Bronze Alloys in Ancient China. Australian National University and Monumenta Serica (1961). http://www.bcin.ca/ Interface/openbcin.cgi?submit=submit\&Chinkey= 63387. Accessed 10 Oct 2017

2. E. Bassoli, A. Gatto, L. Iuliano, M.G. Violante, 3D printing technique applied to rapid casting. Rapid Prototyp. J. 13(3), 148-155 (2007)

3. M. Chanda, S.R. Dinesh, Monitoring the curing of furan resins through the exothermic heat of reaction. Angew. Makromol. Chem. 69(1), 85-98 (1978)

4. Th. Duvaut, Comparison between multiwavelength infrared and visible pyrometry: application to metals. Infrared Phys. Technol. 51(4), 292-299 (2008/3)

5. C. Hull, M. Feygin, Y. Baron, R. Sanders, E. Sachs, A. Lightman, T. Wohlers, Rapid prototyping: current technology and future potential. Rapid Prototyp. J. 1(1), 11-19 (1995)

6. I. Hutchings, G. Martin, S. Hoath, High speed imaging and analysis of jet and drop formation. J. Imaging Sci. Technol.: IS\&T 51(5), 438-444 (2007)

7. D. King, T. Tansey, Alternative materials for rapid tooling. J. Mater. Process. Technol. 121(2), 313-317 (2002)

8. J. Kobliska, P. Ostojic, X. Cheng, X. Zhang, H. Choi, Y. Yang, X. Li. Rapid fabrication of smart tooling with embedded sensors by casting in molds made by three dimensional printing, in Proceedings of SFF Symposium, pp. 468-75 (2005)
9. K.-S. Kwon, W. Kim, A waveform design method for high-speed inkjet printing based on self-sensing measurement. Sens. Actuators, A 140(1), 75-83 (2007)

10. S. Lekakh, V. Richards, E. Druschitz, New method of dynamical measurements of mold thermal properties and applications for casting processes. Trans. Am. Foundry Soc. 115, 333-339 (2007)

11. B.Q. Li, Solidification processing of materials in magnetic fields. JOM 50(2), 1-13 (1998)

12. H. Miyanaji, S. Zhang, L. Yang, A new physics-based model for equilibrium saturation determination in binder jetting additive manufacturing process. Int. J. Mach. Tools Manuf 124(Suppl C), 1-11 (2018)

13. J.-U. Park, M. Hardy, S.J. Kang, K. Barton, K. Adair, D.K. Mukhopadhyay, C.Y. Lee et al., High-resolution electrohydrodynamic jet printing. Nat. Mater. 6(10), 782-789 (2007)

14. R. Ricou, C. Vives, Local velocity and mass transfer measurements in molten metals using an incorporated magnet probe. Int. J. Heat Mass Transf. (1982). http://www.sciencedirect.com/science/article/pii/ 0017931082900369. Accessed 10 Oct 2017

15. R. Singh, Three dimensional printing for casting applications: a state of art review and future perspectives. Adv. Mater. Res. 83, 342-349 (2010)

16. D. Snelling, H. Blount, C. Forman, K. Ramsburg, A. Wentzel, C. Williams, A. Druschitz, The effects of 3D printed molds on metal castings, in Proceedings of the Solid Freeform Fabrication Symposium, pp. 827-45 (2013)

17. D. Snelling, Q. Li, N. Meisel, C.B. Williams, R.C. Batra, A.P. Druschitz, Lightweight metal cellular structures fabricated via 3D printing of sand cast molds. Adv. Eng. Mater. 17(7), 923-932 (2015)

18. D. Snelling, C. Williams, A. Druschitz, A comparison of binder burnout and mechanical characteristics of printed and chemically bonded sand molds, in $S F F$ Symposium, Austin, TX (2014).

https://sffsymposium.engr.utexas.edu/sites/default/ files/2014-018-Snelling.pdf. Accessed 10 Oct 2017

19. Modern Casting. 49th Census of World Casting Production. Modest Growth in Worldwide Casting Market, pp. 26-31 (2015)

20. T. Sugiyama, M. Tahashi, K. Sassa, S. Asai, The control of crystal orientation in non-magnetic metals by imposition of a high magnetic field. ISIJ Int. 43(6), 855-861 (2003)

21. J. Thiel, Thermal expansion of chemically bonded silica sand, in AFS Proceedings, American Foundry Society, Schaumburg, IL USA, vol. 1, no. (10) (2011). https://www.sand.org/resource/resmgr/docs/Research/ Thiel_Paper.pdf. Accessed 10 Oct 2017

22. J. Thiel, S. Ravi, N. Bryant, Advancements in materials for three-dimensional printing of molds and cores. Int. J. Metalcast. 11(1), 3-13 (2017) 
23. USITC, Foundry Products: Competitive Conditions in the US Market (United States International Trade Commission, Washington, 2005)

24. X.D. Wang, T.J. Li, Y. Fautrelle, M.D. Dupouy, J.Z. Jin, Two kinds of magnetic fields induced by one pair of rotating permanent magnets and their application in stirring and controlling molten metal flows. J. Cryst. Growth 275(1), e1473-e1479 (2005) 